\title{
Epidemiology of indications
}

Sir,-One of the main points of Walter Holland's response $^{1}$ to Stephen Frankel's excellent editorial ${ }^{2}$ is that "a new generation of academics and practitioners neglects work undertaken by its predecessors". Among those he blames for this are those of us who were involved with the Department of Health's Project 26.

This project was established after the introduction of the NHS reforms and its purpose was to assist district health authorities in fulfilling their new role of commissioning rather than managing services. One of the many issues the project attempted to address was "needs assessment" 34 and as part of this the project secretariat commissioned research reviews on specific health problems from a number of academic departments. The reviews by $\mathrm{Dr}$ Frankel and Dr Rhys Williams on hip and knee surgery and diabetes respectively have been published $^{56}$ and the remainder should be available within the next few months.

The protocol for these reviews has been published $^{4}$ and contains five references to the need for published reports as a source of information. No constraints were placed on how far back in time a literature search should go and it was up to each academic research team to determine this. A further point countering Professor Holland's contention that previous work was neglected is that a third of the references in an article on needs assessment by two of the public health physicians involved with the project related to work published between 1963 and 1979. ${ }^{8}$ Finally not all the members of the Project belonged to the new generation of practitioners-some of us were clearly old lags rather than young turks.

Defending the activities of Project 26 does not indicate my satisfaction with the dissemination and implementation of research findings. The reasons for the failure to follow through research work are complex but a recent Department of Health report has made major recommendations to overcome some of these. ${ }^{8}$

The important points in Frankel's editorial must not be lost in arguments about blame. The introduction of the NHS reforms is forcing health authorities to be explicit about the services they wish to buy for the residents of their district. This uncomfortable situation had been avoided in the past by leaving clinicians to undertake rationing. The challenge now to health authorities is to identify the mix of services within a fixed budget which will achieve the most "health gain" in terms of a reduction in premature mortality, distress, and disability. Epidemiologists, health economists, and public health physicians are going to have to work together to demonstrate their ability to make a significant contribution to these decisions, otherwise their future is somewhat bleak.

GORDON PLEDGER

Department of Public Health Medicine Newcastle Health Authority

Newcastle

United Kingdom

1 Holland W. Epidemiology of indications (letter). $\mathcal{F}$ Epidemiol Community Health 1992; 46: 170-1.

2 Frankel S. The epidemiology of indications (Editorial). $\mathcal{f}$ Epidemiol Community Health 1991; 45: 257-9.

3 NHS Management Executive. Moving forward - needs, services and contracts. London: Department of Health, 1991.

4 NHS Management Executive. Assessing health care needs. London: Department of Health, 1991 .

5 Frankel SJ, Williams M, Nanchahal K, Coast J. Epidemiological based assessments of need: total hip and knee joint replacement. Bristol: Health Care Evaluation Unit, joint repl.

6 Williams DRR. Diabetes mellitus. Cambridge: University Department of Community Medicine, 1990.

7 Stevens A, Gabbay J. Needs assessment needs assessment. ... Health Trends 1991; 23: 20-23.

Richardson A, Jackson C, Sykes W. Taking research seriously. London: HMSO, 1990.
Richardson A, Jackson

All books reviewed in this issue are available from the BMJ Bookshop, PO Box 295, London, WC1H 9TE. Prices include postage in the UK and for members of the British Forces Overseas, but overseas customers should add $15 \%$ to the value of the order for postage and packing. Payment can be made by cheque in sterling drawn on a UK bank, or by credit card (Mastercard, Visa, or American Express) stating card number, expiry date and your full name.

\section{CORRECTION}

There is an uncorrected error in the paper by Carol Bower and Fiona J Stanley in the April issue (Periconceptional vitamin supplementation and neural tube defects; volume 46, pp 157-161). On page 160, column 2 , line 1 of para 2 should read: "Assuming that the RDA for folate is $400 \mu \mathrm{g} \ldots$..." 